\title{
Partial knowledge in a tip-of-the-tongue state about two- and three-word proper names
}

\author{
J. Richard Hanley and Eleanor Chapman \\ University of Essex, Colchester, England
}

\begin{abstract}
Participants in this study attempted to name 44 famous people in response to reading biographical information about them. Half of the celebrities had names that contained two words (e.g., Gwyneth Paltrow and Sean Penn), and half of them had names containing three words (e.g., Catherine Zeta Jones and Billy Bob Thornton). Half of the names had previously been judged to be of high familiarity (e.g., Gwyneth Paltrow), and half were of lower familiarity (e.g., Billy Bob Thornton). The results showed that when in a tip-of-the-tongue (TOT) state, the participants were able to estimate at above-chance rates whether a celebrity's name comprised two or three words. Accurate information about the number of words was not available to the participants unless they were in a TOT state or had already named the person. Attempts to identify celebrities whose name had three elements were associated with an increased number of TOTs, relative to celebrities whose name had two units, but there was no difference in the number of don't know responses for names containing two or three words. Calculations based on Gollan and Brown (2006) suggested that having three names impaired the phonological but not the semantic stage of lexical retrieval, whereas low familiarity impaired both semantic and phonological retrieval stages.
\end{abstract}

Recalling the names of familiar people is a difficult task, relative to the recall of other types of information that we have about people, such as their occupation or where they are typically encountered (Hanley \& Cowell, 1988; Hay, Young, \& Ellis, 1991). Attempts to retrieve people's names are associated with large numbers of reported tip-of-the-tongue (TOT) states (Burke, MacKay, Worthley, \& Wade, 1991; Yarmey, 1973; Young, Hay, \& Ellis, 1985). In a TOT state, an individual is unable to retrieve a familiar word despite reporting that they know it and feel that its recall is imminent (see Schwartz, 2002, for a review). In Burke et al.'s diary study, retrieval failures and TOT states were reported more frequently for proper names than for object names and abstract words. Recall of proper names can be selectively impaired in patients with anomia (e.g., Hanley \& Kay, 1998; Semenza $\&$ Zettin, 1988) and appears to be particularly difficult for the elderly (e.g., Cross \& Burke, 2004). Cross and Burke showed that older adults were less likely than younger adults to recall names of famous people and more likely to report TOT states despite the fact that the number of don't know (DK) responses was equivalent in the younger and older participants.

The aim of the present study was to investigate further the nature of TOT states for the names of familiar people. One goal was to discover more about the partial knowledge regarding a person's name that individuals have available when in a TOT state. Brown and McNeill (1966) and Koriat and Lieblich (1974) showed that during a TOT state, participants often had access to infor- mation about the number of syllables and the identity of the first and last letters of common nouns that they were trying to recall. Yarmey (1973) reported similar results for names of famous people; participants often knew the first letter and number of syllables when in a TOT state for a person's name. The present study investigated TOT states when participants were attempting to name famous people whose names contained two words (e.g., Liz Hurley and Gwyneth Paltrow) or three words (e.g., Jamie Lee Curtis and Olivia Newton John). The issue under investigation was whether participants who are in a TOT state are able to judge accurately whether the name that they are unable to recall contains two or three words. Following Koriat and Lieblich (1974), we compared performance when the participants were in a TOT state with performance when participants did not know the name (DK). If participants in TOT states genuinely have information available about the number of words that is not simply the result of intelligent guesswork, they should perform significantly better at estimating the number of words in a TOT state than when they report that they do not know the name.

The study also investigated whether the number of words that a name contains has any effect on the probability that it will be retrieved. One possibility is that a name containing three words might actually hinder recall and produce more TOTs than does a name containing two words. The basis for this prediction is the fan effect, which is a property of computational models of person recognition that employ neural networks (Brédart, Valentine, Calder, \& Gassi, 1995; Burton \& Bruce, 1993; Burton,

J. R. Hanley, rhanley@essex.ac.uk 
Bruce, \& Hancock, 1999; Burton, Bruce, \& Johnston, 1990). The fan effect occurs because an association with multiple units in a pool in a network increases competition between the units in that pool. So, the more facts that a participant knows about a person, the more difficult it is likely to be to recall any one of these facts. According to Burton and Bruce, the name retrieval system contains a pool of lexical output units in which separate nodes represent a person's first name and second name. A name containing three words would be associated with three separate nodes. The effect of three nodes, rather than two, will be an increase in competition within the lexical output pool, making it more difficult for each individual unit to achieve sufficient levels of activation to allow recall to take place. A fan effect should, therefore, apply to the recall of the surnames of celebrities such as Jamie Lee Curtis, which should be associated with a greater number of TOTs than are the names of equally familiar people whose names have only two elements (e.g., Liz Hurley). There is no reason to believe that having three names affects earlier stages of word retrieval, so the number of DK responses should be equivalent for people whose name contains two and three units.

These predictions will be formally tested using a procedure recently developed by Gollan and Brown (2006). In common with several models of language production (e.g., Bock \& Levelt, 1994; Burke et al., 1991; Dell, 1986), Gollan and Brown assumed that at least two discrete stages are involved in word retrieval. Stage 1 involves accessing either a semantic or an amodal lexical level of representation (sometimes referred to as a lemma) of the word. Stage 2 involves access to the phonological form of the word. DK responses reflect a failure at Stage 1. TOTs reflect success at Stage 1 but failure at Stage 2. Correct responses reflect success at both stages. Gollan and Brown estimated the probability of failure at Stage 1 by adding the number of correct responses and TOTs, subtracting this sum from the total number of target words, and dividing by the total number of target words. They estimated the probability of failure at Stage 2 by dividing the number of TOTs by the sum of the TOTs and the correct responses. These estimates of the probability of failure at Step 1 and at Step 2 make it possible to assess whether a particular variable - in this case, number of names - has an effect on both semantic and phonological stages of retrieval, on the semantic stage alone, or (as we predict) on the phonological stage alone.

Finally, we also manipulated the rated familiarity of the celebrities that were used as stimuli. In a study that used common names, Harley and Bown (1998) found that more TOTs were reported with words of low familiarity than with those of high familiarity. Importantly, though, low familiarity increased not only the number of retrieval failures, but also the number of DK responses. If familiarity exerts a similar effect on the recall of proper names, familiarity and number of names may affect retrieval in somewhat different ways. Low familiarity should impair both semantic (Stage 1) and phonological (Stage 2) stages of the word retrieval process (Gollan \& Brown, 2006), whereas number of names will affect Stage 2 but not Stage 1.

\section{METHOD}

\section{Participants}

Sixty-four 6th-form college students, who were visiting the psychology department at Essex University as part of an open day, volunteered to take part in the experiment. They were between 17 and 19 years of age. They were tested in groups (10-12 participants per group). None of them had participated in the collection of the normative data that were used to select the experimental materials.

\section{Design}

A two-factor repeated measures design was used to investigate overall recall and number of TOTs. The factors were familiarity (high familiarity vs. low familiarity) and the number of words that a name contains (two vs. three).

\section{Materials}

The target items in the experiment were the names of 44 famous people. The names of half of the famous people contained three words, and the other half contained two words. These names were selected from a larger set that had been rated for familiarity on a scale of 1-5 (where 5 represented maximum familiarity and 1 represented unfamiliar) by 10 participants (students at Essex University). These ratings ensured that the sets of famous people with two and three names were of equivalent overall familiarity and made it possible to divide the famous people into sets of high familiarity and low familiarity.

The 11 highly familiar people whose names contained two words were Jennifer Aniston, Muhammad Ali, Demi Moore, Liz Hurley, Gwyneth Paltrow, Andy Warhol, Clint Eastwood, Barbra Streisand, Jack Straw, Rachel Stevens, and Lucy Liu. Their mean familiarity rating was 4.65 (range $=4.4-4.9$ ). The 11 highly familiar people whose names contained three words were: Catherine Zeta Jones, Martin Luther King, Jon Bon Jovi, Helena Bonham Carter, Jamie Lee Curtis, Iain Duncan Smith, Olivia Newton John, Sven-Göran Eriksson, Tommy Lee Jones, Sarah Jessica Parker, and Nat King Cole. Their mean familiarity rating was also 4.65 (range $=4.4-4.9$ ). The eleven low-familiarity people whose names contained two units were Germaine Greer, Sean Penn, Dean Martin, Ridley Scott, Tim Rice, Clive Woodward, Ashton Kutcher, Brittany Murphy, Roman Polanski, Mary Shelley, and George Orwell. Their mean familiarity rating was 3.84 (range $=3.4-4.2$ ). The 11 low-familiarity people whose names contained three units were Vincent Van Gogh, Billy Bob Thornton, Lee Harvey Oswald, Krishnan Guru-Murthy, Dave Lee Travis, Edgar Allan Poe, Francis Ford Coppola, Kristin Scott Thomas, Melissa Joan Hart, Anna Ryder Richardson, and Robert Louis Stevenson. Their mean familiarity rating was also 3.84 (range $=3.5-4.3$ ).

\section{Procedure}

The participants were given a booklet containing 44 biographical sketches of famous people arranged in a random order (half of the participants received a different booklet in which the order of the items was reversed). For example, the biographical information for Francis Ford Coppola read "Italian-American director of The Godfather and Apocalypse Now." If the participants knew the name of the person described in the sketch, they wrote it down immediately below the biographical information. Names were scored as correct if the final name (the second name for people with two names and the third name for people with three names) was correct. If they could not recall the name, the participants were asked to indicate whether or not they were in a TOT state. Finally, they were asked to estimate whether the person described in the sketch had two names or three names. The written instructions stated that they should estimate the number of names regardless of whether they were in a TOT state or not. This was reinforced by a spoken statement that told the participants that these responses were vital for the success of the experiment. The instructions also indicated that exactly half of the famous names contained two words and exactly half contained three words and that the participants might like to use this information when estimating how many words a name contained. 
The participants were tested individually and worked through the booklet at their own pace. The instructions on the front page of the booklet gave the examples of Sarah Michelle Gellar and Cameron Diaz to clarify what was meant by number of names in this context. A TOT state was defined as follows: "If you know the name and feel that you are about to retrieve it but are unable to bring the name to mind at the moment, then please indicate that you are in a tip-ofthe-tongue state."

\section{RESULTS}

Table 1 reveals the proportion of correctly recalled names, TOT responses, and DK responses (responses on which the participant did not know the name plus incorrect responses) as a function of familiarity and number of words that a name contained.

\section{Correctly Named}

A two-way ANOVA revealed that significantly more high-familiarity names were recalled than names of low familiarity $\left[F(1,63)=241.34, M S_{\mathrm{e}}=2.11, p<.01\right.$, by subjects; $F(1,40)=16.02, M S_{\mathrm{e}}=236.24, p<.01$, by items]. Significantly more names were recalled that contained two words than names that contained three words by subjects $\left[F(1,63)=12.76, M S_{\mathrm{e}}=2.92, p<.01\right]$, but not by items $(F<1)$. The interaction between these factors was not significant by subjects or by items (both $\left.F_{\mathrm{S}}<1\right)$.

\section{Number of TOTs}

There were significantly more TOTs to people whose names contained three words than to names containing two words by subjects $\left[F(1,63)=8.64, M S_{\mathrm{e}}=1.57, p<\right.$ $.01]$ and by items $\left[F(1,40)=4.16, M S_{\mathrm{e}}=12.98, p<\right.$ $.05]$. There was no significant effect of familiarity by subjects or by items $(F \mathrm{~s}<1)$. The interaction between these factors was not significant by subjects $[F(1,63)=1.50$, $\left.M S_{\mathrm{e}}=1.38, p>.10\right]$ or by items $(F<1)$.

\section{Number of DKs}

There were significantly more DKs to names of people of low familiarity than to names of high familiarity $\left[F(1,63)=203.83, M S_{\mathrm{e}}=3.25, p<.01\right.$, by subjects; $F(1,40)=19.47, M S_{\mathrm{e}}=57.54, p<.01$, by items]. There was no effect of number of words by subjects $[F(1,63)=$ $\left.1.08, M S_{\mathrm{e}}=2.09, p>.10\right]$ or by items $(F<1)$. The interaction between these factors was not significant by subjects or by items (both $F \mathrm{~s}<1$ ).

\section{Stages of Retrieval Failure}

Table 2 shows the effect of applying the data in Table 1 to the procedures recommended by Gollan and Brown (2006). The probability of failure at Stage 1 was calculated by adding together the number of correct responses and TOTs, subtracting this sum from the total number of target words, and then dividing by the total number of target words. The probability of failure at Stage 2 was calculated by dividing the number of TOTs by the sum of the TOTs and the correct responses. Table 2 reveals that lowfamiliarity names were associated with large increases in the probability of retrieval failure at both Stage 1 and Stage 2, relative to high-familiarity names. Names that contained three words led to a greater probability of failure than did names with two words at Stage 2, but not at Stage 1. These results therefore confirm the predictions that familiarity affects both semantic and phonological stages of retrieval, whereas the effects of the number of words in a name are confined to the phonological stage.

\section{Partial Knowledge}

A total of 494 TOTs were reported. For 275/494 (.56), the correct number of words was reported. For 218/494 (.44), an incorrect number of words was reported. No response was made on only $1 / 494$ occasions. Thirty-four of the participants (.53) gave more correct number-of-word responses than incorrect responses, 19 (.30) participants gave more incorrect number-of-word responses than correct responses, and $11(.17)$ participants gave the same number of correct number-of-word responses as incorrect responses. A binomial test revealed that significantly more participants made more correct than incorrect responses than made more incorrect than correct responses $(p<.05)$.

A total of 1,294 DK responses were made. Correct recall of the number of words occurred 604/1,294 times (.47), incorrect recall occurred 640 times (.49), and no estimation was made on 50 occasions (.04). Twenty-five of the participants (.39) gave more correct number-of-word responses than incorrect responses, 30 (.47) participants gave more incorrect number-of-word responses than correct responses, and 9 (.14) participants gave the same number of correct number-of-word responses as incorrect responses. A binomial test revealed no significant difference in the number of participants who made more correct than incorrect responses, as compared with the number who made more incorrect than correct responses $(p>.10)$.

Table 1

Mean Overall Proportions of Names Correctly Recalled,

Tip-of-the-Tongue (TOT) Responses, and "Don't Know" Responses (Responses on Which the Participant Did Not Know the Name Plus Incorrect Responses) As a Function of Number of Words and Familiarity, With Standard Deviations

\begin{tabular}{|c|c|c|c|c|c|c|c|c|c|c|c|c|}
\hline \multirow[b]{3}{*}{ Familiarity } & \multicolumn{4}{|c|}{ Named Correctly } & \multicolumn{4}{|c|}{ TOT } & \multicolumn{4}{|c|}{ "Don't Know" } \\
\hline & \multicolumn{2}{|c|}{$\begin{array}{l}\text { Two } \\
\text { Names }\end{array}$} & \multicolumn{2}{|c|}{$\begin{array}{l}\text { Three } \\
\text { Names }\end{array}$} & \multicolumn{2}{|c|}{$\begin{array}{l}\text { Two } \\
\text { Names }\end{array}$} & \multicolumn{2}{|c|}{$\begin{array}{l}\text { Three } \\
\text { Names }\end{array}$} & \multicolumn{2}{|c|}{$\begin{array}{c}\text { Two } \\
\text { Names }\end{array}$} & \multicolumn{2}{|c|}{$\begin{array}{l}\text { Three } \\
\text { Names }\end{array}$} \\
\hline & $M$ & $S D$ & $M$ & $S D$ & $M$ & $S D$ & $M$ & $S D$ & $M$ & $S D$ & $M$ & $S D$ \\
\hline $\mathrm{Hi}$ & .50 & .28 & 4 & .28 & 13 & 0 & .20 & .10 & .37 & .25 & .38 & .24 \\
\hline Low & .19 & .15 & .16 & .22 & .16 & .08 & .22 & .13 & .65 & .20 & .61 & .25 \\
\hline
\end{tabular}


Table 2

Probability of Failure at Stage 1 and Stage 2 of the Word Retrieval Process As a Function of Familiarity and Number of Names, Using Calculations Developed by Gollan and Brown (2006)

\begin{tabular}{cccccc}
\hline & \multicolumn{2}{c}{ Familiarity } & & \multicolumn{2}{c}{ No. of Names } \\
\cline { 2 - 3 } Failure & High & Low & & Two & Three \\
\hline Stage 1 & .38 & .63 & & .51 & .50 \\
Stage 2 & .26 & .51 & & .30 & .42 \\
\hline
\end{tabular}

\section{Number of Words and Number of Syllables}

In order to investigate whether the participants might be using word length to estimate number of names, we examined the number of three-word responses when the participants were in a TOT state for each celebrity whose name contained two words. If syllable length per se was being used, names containing more syllables (first name plus second name) should have been associated with a greater number of three-word responses. However, the correlation between these variables was not significant $(r=.08, p>$ .10 ). We conclude that there is no evidence that number of syllables was being used to estimate number of words.

\section{Bias Toward Two-Word Responses}

We also investigated whether there was any bias toward responding that a name had two words, rather than three, when the participants were in a TOT state or did not know the answer. Of the 494 TOTs that were reported, the participants estimated two words on 346 occasions (.70) and three words on 147 occasions (.30). There was one no response. When they had made a TOT response, 51 participants gave more two-word responses than three-word responses, 4 participants gave more three-word responses than two-word responses, and 9 participants gave the same number of two-word responses as three-word responses. A binomial test revealed that significantly more participants made more two-word than three-word responses than made more three-word than two-word responses $(p<.01)$.

Of the 1,294 responses on which they did not know the name, the participants estimated two words on 831 occasions (.64) and three words on 413 occasions (.32). There were 50 failures to respond (.04). A total of 49 participants (.77) gave more two-word responses than three-word responses, 11 (.17) participants gave more three-word responses than two-word responses, and 4 participants (.06) gave the same number of two-word responses as three-word responses. A binomial test revealed that significantly more participants made more two-word than three-word responses than made more three-word than two-word responses $(p<.01)$.

It is therefore clear that participants show a tendency to respond that a celebrity's name has two rather than three elements when they are unable to recall the person's name. This bias was equally pronounced when the participants were in a TOT state as when they did not know the name. On the one hand, this result is not surprising, given that it is much more common in the general population for names to comprise two words than three words. It is, however, quite striking, given that the participants were told that half of the names in the experiment contained two words and half contained three. It appears that when mak- ing their estimation, the participants were unable to disregard the overall base rate in the population as a whole and were unable to adapt to the frequencies that were operating in the experiment itself. The finding is, therefore, reminiscent of the errors in categorical prediction that were reported by Kahneman and Tversky (1973).

\section{DISCUSSION}

It appears from these results that when they are in a TOT state, participants sometimes know the number of words that the name of a familiar person contains. Such information does not appear to be available when the participants do not know the name; when they do not know the name, participants are just as likely to respond with the wrong number of words as with the correct number of words. Performance in the TOT state does, therefore, appear to genuinely reflect access to information about number of words, rather than sophisticated guessing strategies that might be used to estimate the number of words in the absence of real knowledge (cf. Koriat \& Lieblich, 1974).

An alternative possibility is that the participants did not have access to information about number of words when in a TOT state. Instead, because information was probably available about the number of syllables in a person's name (Yarmey, 1973), the participants may have made their estimation of the number of words on the basis of the syllable length of the person's name. However, there was no significant correlation between the number of syllables in a name and the number of times that a name was considered to comprise three words by the participants who were in a TOT state. It therefore appears that number of words in a name can be added to knowledge about the identity of the first and last letters/phonemes in a word, the number of syllables in a word (Koriat \& Lieblich, 1974), and the grammatical gender of common nouns (Caramazza \& Miozzo, 1997) in the list of those types of information about a name that appear to be available when a person is experiencing a TOT state.

Interestingly, the results also showed that names containing three words were associated with significantly more TOTs than were names with two words. There was no effect of number of words on the number of incorrect or DK responses. Table 2 indicates that the number of words in a name has its effect at the phonological stage (Stage 2), rather than at the semantic stage (Stage 1), of the name retrieval process (Gollan \& Brown, 2006). It therefore exclusively affects the stage of word retrieval at which semantic information about the target item is already available and the phonological word form is being accessed. The detrimental effect of having three names is reminiscent of the effect of age on the ability to retrieve the names of famous people (Cross \& Burke, 2004), which was also associated with increases in the number of TOTs without having any effect on the number of DK responses.

Low familiarity, by contrast, is associated with a reduction in the number of people who are correctly named and also with increases in the number of DK responses. These findings are consistent with results observed by Harley and Bown (1998) when they manipulated the familiarity 
of common names. Although low-familiarity names were not associated with significantly more TOTs than were names of higher familiarity in our study, the number of TOTs in the low-familiarity condition was very large, relative to the number named. Table 2 shows that low familiarity is associated with retrieval failures at both Stages 1 and 2 of the retrieval process (Gollan \& Brown, 2006). Low familiarity therefore appears to affect both the phonological stage and the semantic stage of proper name retrieval; it impairs access to specific semantic information about a person and causes further retrieval problems even when semantic information has been retrieved.

The finding that phonological retrieval is more difficult for names with three elements than for names with two elements is consistent with Burton and Bruce's (1993) computational models of person recognition. Because first and second names are stored as separate nodes in the same lexical output pool in this model, they will interfere with each other. If a name has three elements, interference will be greater than if it has only two, consistent with the fan effect. This is not the only example of the way in which the fan effect appears to influence retrieval of proper names. Stevenage and Lewis (2005) and Valentine, Hollis, and Moore (1999) examined how readily participants could recall the real name of actors and actresses who were associated with a very well known character name (e.g., Calista Flockhart/Ally McBeal). Stevenage and Lewis reported that participants produced fewer correct recalls and many more retrieval failures for actors associated with two names than for equally familiar actors with only a single name (e.g., Meg Ryan). The problem in recalling Calista Flockhart's name may occur at an earlier stage of lexical retrieval in Burton and Bruce's model than did the problem in our study of recalling a name with three elements. Nevertheless, both appear to be examples of situations in which the more facts one knows about a person, the more difficult it is to recall any one of them.

Finally, given that many famous names are stage names chosen by the individuals themselves, it appears counterintuitive that celebrities would choose to be known by threeword stage names if it makes their names more prone to TOTs. One possible explanation is that although having three words in a name appears to hinder recall, it may improve recognition of a person's name as familiar because it makes the name more distinctive. Such a result is suggested by the finding that distinctive faces are recognized as being familiar more readily than typical faces even though it takes longer to classify them as faces (Valentine \& Bruce, 1986). The ability to recognize familiar names containing three separate elements would be an interesting issue for future research on memory for proper names to investigate.

\section{AUTHOR NOTE}

Correspondence should be addressed to J. R. Hanley, Department of Psychology, University of Essex, Colchester, Essex CO4 3SQ, England (e-mail: rhanley@essex.ac.uk).

\section{REFERENCES}

Bock, K., \& Levelt, W. (1994). Language production: Grammatical encoding. In M. A. Gernsbacher (Ed.), Handbook of psycholinguistics (pp. 945-984). New York: Academic Press.

Brédart, S., Valentine, T., Calder, A., \& Gassi, L. (1995). An interactive activation model of face naming. Quarterly Journal of Experimental Psychology, 48A, 466-486.

Brown, R., \& MCNeILl, D. (1966). The "tip of the tongue" phenomenon. Journal of Verbal Learning \& Verbal Behavior, 5, 325-337.

Burke, D. M., MacKay, D. G., Worthley, J. S., \& Wade, E. (1991). On the tip of the tongue: What causes word finding failures in young and older adults. Journal of Memory \& Language, 30, 542-579.

Burton, A. M., \& Bruce, V. (1993). Naming faces and naming names: Exploring an interactive activation model of person recognition. $\mathrm{Mem}$ ory, 1, 457-480.

Burton, A. M., Bruce, V., \& Hancock, P. J. B. (1999). From pixels to people: A model of familiar face recognition. Cognitive Science, 23, 1-31.

Burton, A. M., Bruce, V., \& Johnston, R. A. (1990). Understanding face recognition with an interactive activation model. British Journal of Psychology, 81, 361-380.

Caramazza, A., \& Miozzo, M. (1997). The relation between syntactic and phonological knowledge in lexical access: Evidence from the "tipof-the-tongue" phenomenon. Cognition, 64, 309-343.

Cross, E. S., \& Burke, D. M. (2004). Do alternative names block young and older adults' retrieval of proper names? Brain \& Language, 89, 174-181.

Dell, G. S. (1986). A spreading-activation theory of retrieval in sentence production. Psychological Review, 93, 283-321.

Gollan, T. H., \& Brown, A. S. (2006). From tip-of-the-tongue (TOT) data to theoretical implications in two steps: When more TOTs means better retrieval. Journal of Experimental Psychology: General, 135, 462-483.

Hanley, J. R., \& Cowell, E. S. (1988). The effects of different types of retrieval cues on the recall of names of famous faces. Memory $\&$ Cognition, 16, 545-555.

HANLEy, J. R., \& KAY, J. (1998). Proper name anomia and anomia for the names of people: Functionally dissociable impairments? Cortex, 34, 155-158.

HARLEY, T. A., \& Bown, H. E. (1998). What causes a tip-of-the-tongue state? Evidence for lexical neighbourhood effects in speech production. British Journal of Psychology, 89, 151-174.

HaY, D. C., Young, A. W., \& Ellis, A. W. (1991). Routes through the face recognition system. Quarterly Journal of Experimental Psychology, 43A, 761-791.

Kahneman, D., \& Tversky, A. (1973). On the psychology of prediction. Psychological Review, 80, 237-251.

Koriat, A., \& LIEBLICH, I. (1974). What does a person in a "TOT" state know that a person in a "don't know" state doesn't know? Memory \& Cognition, 2, 647-655.

Schwartz, B. L. (2002). Tip-of-the-tongue states: Phenomenology, mechanism, and lexical retrieval. Mahwah, NJ: Erlbaum.

SemenZa, C., \& ZetTin, M. (1988). Generating proper names: A case of selective inability. Cognitive Neuropsychology, 5, 711-721.

Stevenage, S. V., \& Lewis, H. G. (2005). By which name should I call thee? The consequences of having multiple names. Quarterly Journal of Experimental Psychology, 58A, 1447-1461.

VAlentine, T., \& Bruce, V. (1986). Recognizing familiar faces: The role of familiarity and distinctiveness. Canadian Journal of Psychology, 40, 300-305.

Valentine, T., Hollis, J., \& Moore, V. (1999). The nominal competitor effect: When one name is better than two. In M. Hahn \& S. C. Stoness (Eds.), Proceedings of the 21st Annual Meeting of the Cognitive Science Society (pp. 749-754). Mahwah, NJ: Erlbaum.

YARMEY, A. D. (1973). I recognize your face but I can't remember your name: Further evidence on the tip-of-the-tongue phenomenon. $\mathrm{Mem}$ ory \& Cognition, 1, 287-290.

Young, A. W., Hay, D. C., \& Ellis, A. W. (1985). The faces that launched a thousand slips: Everyday difficulties and errors in recognizing people. Quarterly Journal of Experimental Psychology, 38A, 297-318.

(Manuscript received January 9, 2006; revision accepted for publication July 10, 2007.) 